\title{
Consultoria Colaborativa: uma proposta de Intervenção Escolar
}

\author{
Collaborative Consulting: a proposal for School Intervention \\ Leonardo Augusto Couto Finelli*, Eliane Marques de Sousa**, Gabrielle Ferreira Silva** \\ Faculdades Integradas do Norte de Minas - FUNORTE, e da Faculdade de Saúde Ibituruna - FASI, **Faculdade de Saúde Ibituruna - FASI
}

\begin{abstract}
Resumo
A Consultoria Colaborativa é definida como um processo que visa adicionar e ampliar saberes e práticas, formando uma rede de apoio ao acadêmico e a educação. Essa pesquisa analisou a compreensão dos profissionais da educação de duas escolas públicas de Montes Claros, MG - Brasil. Investigou-se as percepções dos participantes sobre 0 processo de Consultoria Colaborativa, considerando à eficácia da técnica. A pesquisa se deu por entrevista semiestruturada e análise de discurso. Os resultados demonstraram a multidisciplinaridade de conhecimentos envolvidos no processo como o principal benefício ao desenvolvimento das crianças. Os respondentes sugeriram sua implementação como política pedagógica constante.

Palavras chave: Consultoria Colaborativa, Intervenção Escolar, Mediação Escolar, Psicólogo.
\end{abstract}

\begin{abstract}
The Collaborative Consulting is defined as a process aimed in expanding knowledge and school practices, forming a network to support the academic education. This paper analyzed the understanding of education professionals from two public schools of Montes Claros, Minas Gerais - Brazil. It investigated the perceptions of the participants about the process of Collaborative Consulting, considering the effectiveness of the technique. The research was given by semi-structured interviews and discourse analysis. The results showed that the knowledge multiplicity which is involved in the process as the main benefit to the development of children. Respondents suggested its implementation as a constant pedagogical policy.

Keywords: Collaborative Consulting, School, Intervention, School Mediation, Psychologist
\end{abstract}

É notório que os últimos anos têm sido marcados por uma serie de transformações econômicas, sociais, tecnológicas, dentre outras. Valore (2003) citado por Carvalho (2008) afirma que não é mais possível ignorar o fato de que novas estratégias e técnicas têm sido exigidas dos profissionais. Isso se dá em função do processo de globalização, imprevisibilidade dos novos tempos, do avanço tecnológico, bem como do reconhecimento do paradigma da incerteza. O que tem produzido um incremento de exigência quanto à formação escolar, a fim de minimizar o lapso entre essa e as exigências atuais do mundo do trabalho.

Nesse contexto, o ambiente escolar tem sido atravessado por diferentes realidades sociais, culturais, econômicas, que tem provocado uma ampla discussão sobre as dificuldades do ensinar nos dias atuais.

Campos (2004) também explora essas diversas mudanças sociais ocorridas ao longo dos anos e que fizeram emergir a necessidade de recorrer a novos processos, proporcionando novas oportunidades de aprendizagem.. Assim, faz-se mister a inclusão do profissional psicólogo num trabalho interdisciplinar, a fim de repensar os desafios contemporâneos do aprender.

Santana; Pereira e Rodrigues (2014) definem psicologia escolar como sendo

uma área de conhecimento e de atuação profissional que tem como objeto o encontro entre o sujeito humano e a educação, com ênfase nas relações estabelecidas entre os processos psicológicos e os processos educacionais (SANTANA; PEREIRA; RODRIGUES, 2014, p. 231).

O psicólogo propiciaria situações onde as práticas sociais teriam condições de ser ressignificadas, assim como a percepção a cerca da sua atuação. Neste sentido o trabalho do psicólogo implica num reconhecimento das dimensões das quais ele se relaciona com os aspectos teóricos e metodológicos a serem utilizados. Isso implica em trabalhar enquanto pesquisado/interventor.

Dias, Patias e Abaid (2014) consideram que o psicólogo não deve apresentar respostas prontas, mas deve interagir com os demais profissionais da área educacional a fim de construírem juntos soluções viáveis nesse contexto. Para tanto, ainda segundo essas autoras, o profissional psicólogo deve manter uma postura crítica e criativa, não se fechando aos vários desafios e potencialidades que permeiam esse processo.

Um importante papel do psicólogo escolar pode ser evidenciado a partir da execução de um trabalho conjunto, interdisciplinar, colaborativo entre familiares, professores e demais profissionais envolvidos no trato pedagógico com o aluno. Dentre as várias estratégias possíveis de trabalho, a Consultoria Colaborativa tem despontado como uma alternativa para a compreensão, análise e intervenção escolar.

Bello, Machado e Almeida (2012) definem a Consultoria Colaborativa como sendo uma proposta de atuação conjunta com o intuito de mutuamente resolverem os problemas através do compartilhamento de saberes e responsabilidades. Para a consecução do mesmo sugerem o cumprimento de algumas etapas, tais como: contato com os envolvidos (professora, diretora, pais, etc), elaboração de um roteiro de atividades a serem desenvolvidas (observações do aluno em diversos ambientes escolares, entrevistas com familiares e profissionais pedagógicos), entrevista devolutiva com os participantes para fins de compartilhamento das observações feitas, elaboração conjunta de proposta de intervenção e reavaliação dessas propostas caso necessário.

Por sua vez, Silva e Mendes (2009) destacam como benefícios: oportunidade entre os envolvidos de 
compartilhar habilidades, aumento na comunicação entre os envolvidos, o que proporciona maior compartilhamento de recursos materiais e humanos; facilitação da oferta de serviços com base nas necessidades de aprendizagem acadêmica e social; desenvolvimento de programas de intervenções efetivos e criativos; oportunidades entre os envolvidos de aumentar e melhorar seu conhecimento conceitual e tecnológico assim como suas habilidades interpessoais e suas atitudes intrapessoais.

O suporte da consultoria colaborativa exige que os parceiros, neste caso, professores, outros membros da escola e profissionais especializados, sejam equivalentes estejam engajados num processo conjunto de tomadas de decisões, trabalhando em direção a um objeto comum. Segundo Silva e Mendes (2009) para que o bem estar dos alunos seja alcançado, faz-se necessário a formação de parcerias colaborativas entre professores, psicólogos e outros profissionais escolares.

Friend e Cook (1990) corrobora afirmando que as condições necessárias para a colaboração são: existência de um objeto comum, equivalência entre participantes, participação de todos, compartilhamento de responsabilidades, compartilhamentos de recursos e voluntarismo.

O modelo de consultoria colaborativa existe desde 1990 na literatura educacional (IDOL; PAOLUCCI-WHITCOMB; NEVIN, 2000; KAMPWIRTH, 2003; PUGACH; JOHNSON, 1995; WEST; IDOL, 1989). Consultoria é um processo que tem seis características: 1) é uma ajuda ou processo de resolução de problemas; 2) ocorre entre alguém que recebe ajuda e alguém que dá a ajuda e que tem a responsabilidade pelo bem estar de uma terceira pessoa; 3) é uma relação voluntária; 4) tanto quem dá ajuda quanto quem a recebe compartilha a solução do problema; 5) a meta é ajudar a resolver um problema de trabalho atual de quem busca a ajuda; e 6) quem ajuda se beneficia da relação, de modo que os futuros problemas poderão ser controlados com mais sensibilidade e habilidade.

A Consultoria Colaborativa Escolar (CCE) pode ser definida como um processo no qual um consultor trabalha em uma relação igualitária e não hierárquica com um consultante, em geral professores e pais, de forma a reunir os esforços dos mesmos para tomar decisões e implementar intervenções que melhor atendam os interesses educacionais dos alunos (KAMPWIRTH, 2003 apud SILVA; MENDES, 2009, p. 2133).

A meta é encontrar caminhos para garantir o sucesso de qualquer aluno na educação regular e sua efetividade depende da comunicação honesta e autêntica do consultor. (KAMPWIRTH, 2003 apud SILVA; MENDES, 2009).

Essa metodologia de trabalho (Consultoria Colaborativa) pode se tornar um importante recurso aos professores e supervisores pedagógicos na consecução de seus objetivos; e aos profissionais psicólogos que atuam nessa área, uma ferramenta indispensável para promoção de um diálogo interdisciplinar e fomentador de soluções eficazes para os problemas da aprendizagem.
Assim, pretende-se com esse trabalho ampliar a discussão acerca dessa estratégia interventiva, analisar suas deficiências e potencialidades, bem como compreender a percepção dos benefícios dessa como estratégia de intervenção escolar interdisciplinar em escolas de Montes Claros/MG.

\section{Método}

Este projeto contempla uma pesquisa exploratória, qualitativa, de corte transversal. Deu-se com delineamento de estudo de campo.

A proposta amostral, desenvolvida por conveniência, se deu com a investigação com cinco profissionais de duas escolas, nas quais foram desenvolvidas o trabalho de Consultoria Colaborativa no $2^{\circ}$ semestre de 2013 por acadêmicos do $8^{\circ}$ período do curso de Psicologia de uma Instituição de Ensino Superior do Norte de Minas.

Aos participantes foi aplicado um questionário semi estruturado. Este foi composto por parte inicial contemplando dados sociodemográficos, com itens fechados; e nove questões abertas. Dessas duas foram questões norteadoras, cujo intuito era investigar a percepção dos profissionais em relação ao processo de Consultoria Colaborativa; as demais consideravam as percepções e opiniões dos respondentes sobre o processo de Consultoria Colaborativa.

A partir desse material, houve a compilação dos dados. Esses foram posteriormente analisados por procedimentos de análise de discurso (BARDIN, 1977) e subsidiaram a geração dos relatórios necessários para a conclusão do presente artigo.

\section{Resultado}

Foram entrevistadas 05 (cinco) profissionais, sendo duas diretoras, uma supervisora pedagógica e duas professoras, sendo que uma das professoras acumula cargo também de supervisora pedagógica. Possuem entre 09 (nove) e 30 (anos) de atuação escolar, e com mais de 04 (quatro) anos na atual instituição de ensino.

Ao analisar a percepção das entrevistadas sobre o processo de Consultoria Colaborativa todas demonstraram compreender a importância dessa proposta interventiva. Porém, as respostas foram emitidas sob pontos de vista diferente (alguns deles descreveram inclusive a estruturação dessa proposta de trabalho).

Todas as respondentes identificaram a Consultoria Colaborativa como uma parceria estratégica para melhor compreensão da criança e apresentaram congruência quanto à percepção dos resultados favoráveis dessa.

Respondente M.A.: Achei bacana. A criança ganhou mais gosto pela aprendizagem. Foi muito produtivo.

Respondente S.M.: Forma diferente de ver as questões dentro da escola. Não se limitar ao lado pedagógico. Possibilitou analisar os problemas da criança por outros ângulos.

Tais percepções podem ser verificadas nos excertos abaixo: 
Os respondentes demonstraram satisfação em participar do processo de intervenção, sendo que apenas uma das entrevistadas reconheceu não ter sido possível participar "de forma adequada”, com mais tempo.

Ao serem questionadas sobre a importância dessa estratégia de intervenção em Escolas Publicas de Montes Claros, houve consenso em afirmar que todas as escolas deveriam ter um profissional psicólogo desenvolvendo esse tipo de trabalho.

Respondente S.M.: Se as escolas tivessem um profissional ao menos uma vez por semana o ganho para a qualidade do ensino da escola, inserção do aluno seria grande. Consequentemente melhoraria a qualidade do ensino.

Quando investigada a eficácia da Consultoria Colaborativa quanto ao processo de aprendizagem do aluno, afirmam que essa metodologia mostrou-se importante dada a possibilidade de se construir multiprofissionalmente estratégias de intervenção a partir de uma visão ampliada sobre o aluno. A maioria delas relatou avanço no desenvolvimento cognitivo/comportamental do aluno.

Houve também concordância unânime quanto a percepção de que houve evolução da criança tanto em termos comportamentais observáveis quanto em termos cognitivos/aprendizagem.

Respondente M.A.: É importante porque o aluno desenvolveu muito. Começou a falar, interesse pelo processo do aprender. Ele passou a querer fazer.

Além disso, as respondentes não elencaram dificuldades para a realização do processo de Consultoria Colaborativa, exceção pela da falta de espaço físico da escola e pelo distanciamento da família. As mesmas concordaram que o tempo de realização da Consultoria Colaborativa poderia ter sido maior, possibilitando a implementação das estratégias pensadas.

Respondente D.: Teria mais tempo para vir à escola; participação maior e prolongada; deveria ter inicio, meio e fim.

\section{Discussão}

Considerando os resultados apresentados, verifica-se que os profissionais entrevistados reconhecem a Consultoria Colaborativa como importante estratégia de intervenção para a promoção de desenvolvimento do aluno. No entanto, as respostas emitidas sugerem um conhecimento superficial acerca desse processo. Os respondentes percebem também que a interação entre familiares, escola e consultor psicólogo produz resultado positivo no desenvolvimento do discente, tendo sido descritos resultados principalmente comportamentais, ou melhoria na interação social das crianças avaliadas. Porém a percepção sobre os avanços cognitivos foram de menor intensidade. Esse resultado sugere que mesmo num espaço curto de tempo é possível implementar estratégias que sejam funcionais e que possibilitem mudanças sensíveis de comportamento; mas para que as alterações cognitivas sejam percebidas com maior visibilidade isso demandaria um maior tempo de execução, acompanhamento e reavaliação das estratégias propostas.

Cabe ressaltar que a pratica foi realizada no $2^{\circ}$. Semestre de um ano letivo, como parte das atividades práticas de uma disciplina de formação do curso de psicologia. Nesse sentido, o trabalho de campo realizado nas escolas ocorreu num tempo limitado, em função da estruturação do calendário acadêmico. Em tal tempo restrito não foi possível realizar todas as etapas que compõem o processo de CC, e as fases de feedback e reavaliação das intervenções não puderam ser realizadas. A partir disso pode-se inferir que a ruptura nesse processo pode ter alterado a percepção dos profissionais quanto a maior efetividade - especialmente no tocante ao desenvolvimento cognitivo dos alunos - das intervenções realizadas. Acredita-se que a realização de um trabalho sequencial de consultoria colaborativa possibilitaria um maior êxito nos resultados das intervenções.

\section{Conclusão}

Com esse trabalho, reconhece-se que a proposta do trabalho de Consultoria Colaborativa é viável. Os pesquisadores, assim como as respondentes conseguem verificar grandes ganhos em termos de aprendizado e comportamentais associados as crianças que participaram do trabalho de Consultoria Colaborativa.

Não obstante, ambos reconhecem que tal proposta, por ter se dado como atividade prática de estágio e não ter sido concluída como inicialmente prevista em função do termino do semestre letivo, pode não ter alcançado todos os resultados que eram vislumbrados inicialmente. Mesmo assim, consideram-se os incrementos para os participantes.

Acredita-se que a realização da proposta tal qual prevista poder-se-ia alcançar resultados de maior soma. Para tal a proposta das pesquisadoras, corroborada pelas entrevistadas, é de que a Consultoria Colaborativa deveria ser implementada como política pedagógica constante e não apenas uma forma de intervenção paliativa ou remediativa frente a uma situação problemas pontuais.

Verifica-se que o grande benefício reconhecido pelas respondentes é de que, por se tratar de proposta de parceria, há redução do trabalho da gestão escolar em tamponar problemas pontuais. Além disso, as mesmas consideram o caráter de multidisciplinaridade como fundamental para o progresso dos acadêmicos.

Por fim, mas não menos importante, reconhece-se ainda que o grupo de respondentes apresenta longa experiência em gestão escolar, porém essa não parece estar associada a busca de capacitação ou novas estratégias de intervenção para as situações problema cotidianas. Assim a apresentação da Consultoria Colaborativa mostrou-se como possibilidade que gerou grandes expectativas em tal grupo, já que mesmo que descontinua a proposta, por ter sido apresentada, pôde leva-las a reflexão e a busca de novas informações e/ou profissionais para retomar tal trabalho. 
Reconhece-se, portanto, as limitações dessa pesquisa quanto à experiência dos profissionais e extensão da prática realizada. A limitação temporal do estágio, associada a pouca experiência das consultoras, e aos demais elementos limitadores citados implicam em apenas sucesso parcial. Nesse sentido, reconhecidos tais elementos propõe-se que novas propostas sejam levadas a campo, perpassando tais limitações para que se possa avaliar novamente e de modo mais adequado os resultados do processo de Consultoria Colaborativa.

\section{Referências}

Bardin, L. (1977). Análise de conteúdo. Lisboa: Edições 70.

Bello, S.F., Machado, A.C. \& Almeida, M.A.

(2012). Parceria colaborativa entre fonoaudiólogo e professor: análise dos diários reflexivos. Rev. psicopedag.[online], 29(88), 46-54. http://pepsic.bvsalud.org/pdf/psicoped/v29n88/ 07.pdf

Campos, B.C. (2004). Novas Dimensões do Desempenho e Formação de Professores. Discursos: Perspectivas em Educação, (2), 13-26. http://hdl.handle.net/10400.2/155

Carvalho, R.G.G. (2008). A dimensão relacional da intervenção dos serviços de psicologia nas escolas. Psicologia: Reflexão e Critica, 21(1), 119-124. http://www.scielo.br/pdf/prc/v21n1/a15v21n 1.pdf
Dias, A.C.G., Patias, N.D. \& Abaid, J.L.W. (2014). Psicologia Escolar e possibilidades na atuação do psicólogo: algumas reflexões. Psicologia Escolar e Educacional, 18(1), 105-111. http://www.scielo.br/pdf/pee/v18n1/v18n1a11.pdf

Friend, M. \& Cook, L. (1990). Collaboration as a predictor for success in school reform. Journal of Educational and Psychological Consultation, 1(1), 69-86. http://www.tandfonline.com/doi/abs/10.1207/s 1532768xjepc0101_4

Kampwirth, T.J. (2003). Collaborative consultation in the schools: effective practices for students with learning and behavior problems. New Jersey: Pearson Education.

Minayo, M.C.S. (2000). O desafio do conhecimento: pesquisa qualitativa em saúde. 7. ed. São Paulo: Hucitec.

Santana, A.C., Pereira, A.B.M. \& Rodrigues, L.G. (2014). Psicologia Escolar e educação superior: possibilidades de atuação profissional. Psicologia Escolar e Educacional, 18(2), 229-237. http://www.scielo.br/pdf/pee/v18n2/1413-85 57-pee-18-02-0229.pdf

Silva, A.M. \& Mendes, E.G. (2009). O Papel do Psicólogo na Prevenção de Problemas de Comportamento. Anais do V Congresso Brasileiro Multidisciplinar de Educação Especial. Londrina-PR. 